\title{
Socio-Economic Status Of Parents And Its Effects On The Academic Performance Of Students Of Yamfo Anglican Senior High School In The Brong Ahafo Region Of Ghana
}

\author{
Benedict Osei-Owusu \\ Department of Interdisciplinary Studies, College of Agriculture Education, Mampong-Ashanti, \\ University of Education Winneba, GHANA-WEST AFRICA. \\ Eric Twum Ampofo \\ Department of Interdisciplinary Studies, College of Agriculture Education, Mampong-Ashanti, \\ University of Education Winneba, GHANA-WEST AFRICA.
}

\section{Kwadwo Oteng Akyina}

Department of Interdisciplinary Studies, College of Agriculture Education, Mampong-Ashanti, University of Education Winneba, GHANA-WEST AFRICA.

\section{Robert Ampomah}

Department of Interdisciplinary Studies, College of Agriculture Education, Mampong-Ashanti, University of Education Winneba, GHANA-WEST AFRICA.

\section{Esther Osei-Owusu}

Department of Home Economics, Amaniampong Senior High School, Mampong, Ashanti, Ghana

\begin{abstract}
The purpose of this research was to investigate the effects of parents' socio-economic status on the academic performance of Yamfo Anglican Senior High School Students in the Tano North District of the Brong Ahafo Region of Ghana. In order to have an adequate representation of the population of the study, eighty (80) students were selected from the second year class using a simple random sampling technique. The total population of second year class was 213 students. The study was a survey type and therefore a self-designed questionnaire was adopted to collect data. The data was therefore analysed via simple frequencies, tables and percentages. The socio-economic status of parents for this study was denoted by parents' educational level, parents' occupational level, parents' income level and parental care. The findings of the study were that, parents' educational level, parents' occupational level, parents' income level and parental care have an effect on the academic performance of students of Yamfo Senior High School. Therefore, it is strongly recommended that unemployment should be controlled. Also, needy but brilliant students should be provided with scholarships, free textbooks and stationery. In addition, government should take steps to raise the socio-economic status of its citizenry.
\end{abstract}

Keywords: Parents' Educational Level, Parents' Occupational Level, Parents' Income Level Parental Care and Academic Performance 


\section{INTRODUCTION}

Education is the best legacy a nation can give to her citizens especially the youth. This is because the development of any nation depends largely on the quality of education of such a nation. Education is considered as the development of the endowed capacities in the individual, which will enable the one to control his/her environment and fulfill his/her possibilities to a large extent (Saxton, 2000). This notion is important in that educated individuals can control the environment, build upon it and then transform it positively to influence the lives of people in all aspects (Mbathia, 2005). Indeed, in this epoch of technological revolution, education is considered as the first step for every human activity. It plays a vital role in the development of human capital and is linked with an individual's wellbeing and opportunities for better living (Battle \& Lewis, 2002). In truth, quality education ensures the acquisition of knowledge and skills that enable individuals to increase their productivity and improve their wellbeing. Much is then said that formal education remains the vehicle for socio-economic development and social mobilization of any society.

Many academic institutions are in the business of periodically assessing the performance of their students through varied means in an attempt to guarantee academic success as well as enhance the chances of their graduates on the labour market. According to Head (1990) the placement of value judgment on performance of students to determine their worth is an integral aspect of the entire educational process. The importance of success academically in one's life cannot be overemphasized. Success in teaching and learning has the potential of motivating learners to aspire for higher learning. Indeed, granting the importance of academic performance is rarely questioned, however the factors that influence and mediate it have been elusive (Elliot, 2007). In reality, amongst the various predictors of academic performance, there are likely to be some interactions between each other, and therefore the effect of one factor on the academic performance may be indirectly reflected through others.

Socio-Economic Status (SES) is an economic and sociologically combined total measure of a person's work experience and of an individual's or family's economic and social position in relation to others based on income, education and occupation (National Center for Education Statistics, 2008). According to Parson, Stephanie and Deborah (2001), socio-economic status is an expression which is used to differentiate between people's relative position/status in community regarding family income, political power, educational background and occupational status. It is a definite background variable that represents a feature of the social structure in society (Oakes \& Rossi, 2003). In fact, the socio-economic status of a parent is a combined measure of a parent's level of education, level of occupation and level of income (Jeynes, 2002).

Ghana, like any other "third world country" is suffering from economic crisis which largely affects the socio-economic status of its populace. One in six school-aged children is deprived of education (National Center for Education Statistics, 2008). The academic performance of students is negatively correlated with the socio-economic status of parents (Eamon, 2005). It is an established fact that families where parents are privileged educationally, socially and economically inspire a higher level of academic achievement in their offspring. Indeed, the offer higher level of psychological support for their children through enriched atmosphere that promotes and encourages the development of skills required for success at school (William, 1993). Research further indicates that children from low SES develop academic skills far more slowly compared to children from high SES background. In fact, it is understood that low socioeconomic status of parents negatively and depressingly affect children's academic achievement because due to the low socio-economic status, children do not get access to important 
educational resources and this generates additional stress and tension at homes (Eamon, 2005; Jeynes, 2002).

\section{Statement of the Problem}

Despite many educational reforms, policies, measures and programs that have been put forth time immemorial, the quality of education and an accelerated academic performance of students in Ghana continue to be a mirage. The academic performance of students in Yamfo Anglican Senior High School in the Tano-North District of the Brong-Ahafo Region of Ghana has been falling over the years. This unpleasant state of affairs can be attributed to varied factors and reasons. However, one variable that has contributed to this persistent situation is the socio-economic status of parents. Socio-economic status of parents as it's were, is believed to affect the academic performance of students (Heyneman, 2005). Depending on the level of academic achievement, individuals are characterized as high, average and low achievers. A number of studies aver that academic performance of students is dependent on many variables of which the social and economic classification of parents is inclusive (Eamon, 2005). Indeed, the division of society into different classes and the association of parents with a certain class and its linkage with the education of their children is an important feature of our society. It is therefore imperative to look into the socio-economic status of parents and its effects on the academic performance of their wards.

\section{SocioEconomic Status (SES)}

\section{REVIEW OF LITERATURE}

Socioeconomic status is a term which comprises two variables: the social and the economic variables. Social status is acquired by the position one occupies in a society whilst the economic status is associated with the wealth of a person. In fact, the socioeconomic status has always been measured by the same parameters by experts from varied fields including sociologists, educationists and psychologists. Parson, Stephanie and Deborah (2001) define socio-economic status as an expression which is used to differentiate between people's relative status in community regarding family income, political power, educational background and occupational status. Also, Saifi and Mehmood (2011) submit that socio-economic status is a combined measure of an individual or family's income and social position relative to others based on income, education and occupation. In fact, it is a definite background variable that represents a feature of the social structure in society (Oakes \& Rossi, 2003).

Socio-economic status is typically delineated into three categories, thus high SES, middle SES and low SES to describe the three areas family or an individual may fall into. Thus, the concept "class" or "status" implies some people are either superior or inferior in some respect. One can be found at the top, middle or at the bottom. Socio-economic status therefore means that the social and economic standing of a person depends on these key variables, thus wealth, education, occupation and influence. Indeed, this index of social position utilizes occupation, education and residence to locate people within the status hierarchy (Agyemang, 1979).

\section{Academic Performance}

Academic instruction is arguably the primary business of education. To this end, schools are expected to influence students' learning, socialisation, and even vocational preparedness. Despite the attention paid to a broad definition of educational outcomes, however, academic performance remains central. Students' academic performance is a term that appears frequently married in higher education discourse. Academic performance is a multidimensional construct composed of the skills, attitudes, and behaviors of a learner that contribute to academic success in the classroom (Hijazi \& Naqvi, 2006). It is a satisfactory and 
superior level of performance of students as they progress through and complete their school experience (Tinto, 1993). The implication of this definition is underscored by research which repeatedly demonstrates that the vast majority of students who withdraw from school do so for no reason other than poor academic performance (Hijazi \& Naqvi, 2006; Tinto, 1993).

Although the importance of academic achievement is rarely questioned, reaching unanimity regarding its measurement has been elusive. The measurement of students' academic performance continues to be a controversial topic among policymakers, measurement experts, and educators (Elliot, 2007; Johnson, 2003). Researchers have used a variety of ways to measure academic achievement such as report card grades, grade point averages, standardized test scores, teacher ratings, other cognitive test scores, grade retention, and dropout rates (Burns \& Darling, 2002). However, for the purposes of this study, student academic performance is defined by the degree to which a student is able to accomplish a given class work in the school setting.

\section{Parents' Education Level on the Academic Performance of Students}

Parents are the most immediate relation of a child. Educated parents better understand the educational needs and their children's aptitude. They, thus help their children in their early education which affects their proficiency in their relative area of knowledge. Parents' education or academic background definitely contributes immensely toward the academic life of children. According to Grissmer (2003), parents' level of education is the most important factor affecting students' academic achievement. Taiwo (1993) submits that parents' educational background influence the academic achievement of students. This, according to him, is because the parents would be in a good position to act as second teachers to their children; and even guide and counsel them on the best way to perform well in education and provide the necessary materials needed by them.

From a similar point of view, Annette (2003) argues that academic attainment of parents had a positive and statistically significant effect on the educational attainment of their wards. Tinto (1993) also reveals that there is a strong relationship between a student's academic output and his or her parent's educational qualifications. For him, parents' academic achievements enable the individual student to build a positive self-efficacy image about themselves and make them feel they are capable of succeeding in their academic pursuit. This finding further reinforces the position of Girves and Wemmerus (1988), however Tinto did not touch on the importance of other factors like income, occupation and school within which they study which was an important point stressed by Girves \& Wemmerus. This means, parents' education alone might not be enough in guaranteeing higher academic performance.

\section{Parents' Occupation Level on the Academic Performance of Students}

Occupational prestige as one of the components of SES encompasses income and educational attainment. Occupational status corresponds to the educational attainment of an individual through which obtaining better job and retaining better positions becomes inevitable. It consequently becomes an indicator and measure of social position/status in a society, hence describing job characteristics, decision making ability and emotional control, and the psychological demands on the job (McNeal, 2001). Indeed, occupational status shows achievement in skills required to do a particular job. Jobs found at the apex of SES classification provide more challenging work and ability and greater control over working conditions. However, jobs with lower rankings were less valued and were paid significantly less and were more laborious, physically hazardous and provide less autonomy (Janny \& David, 2005). Many scales rank occupation based on the level of skill involved, thus from unskilled to skilled, manual to mechanic, unprofessional to professional or use a combined measure using the 
education level needed and the income involved (Dills, 2006). In today's world, identifying the right occupation has become a dilemma. In this regard, occupations that are in line with an individual's education are quite hard to find, hence compromises on occupations is inevitable as long as the financial reward addresses the basic needs of an individual (Graetz, 1995).

Combs (1985) argues that in virtually all nations, children of parents high on the occupational scale have far better chance of getting into good secondary schools and from there into the best colleges and universities. Combs, also asserts that a great number of children whose parents are at the bottom of the occupational hierarchy are not as inclined to seek or gain access to available educational facilities compared to children whose families are located at the middle or top of the hierarchy. Indeed, parents' occupation level has a significant effect on the academic achievement of their wards. It plays a remarkable role in students' academic advancement and achievement. Good parental occupation has a positive effect on the academic performance of children because such parents found themselves in well-paid jobs which afford them opportunity to provide material support for their children's education. Dills (2006) in a similar view finds that students from the bottom quartile consistently perform below average compared to students from the top quartile of the occupational status.

\section{Parents' Income Level on the Academic Performance of Students}

A person's income can be denoted invariably as wages, salaries, profits, rents and any flow of earnings received. It also includes revenue generation in the form worker compensation, social security, pensions, interests or dividends, royalties, trusts, alimony and other governmental, public or family financial assistance (Keynes, 2008). Income is a commonly used measure of SES because it is relatively easy to figure it out for most individuals. Income inequality is most often measured with the use of the Gini coefficient, where 0 connotes perfect equality and 1 means perfect inequality. Low income families focus on meeting immediate needs and do not accumulate wealth that could be passed on to future generations, hence increasing inequality. Families with higher and expendable income, on the other hand, accumulate wealth and focus on meeting immediate needs while being able to consume and enjoy luxuries and weather crises (Boushev, 2005).

According to number of research works conducted, the predictive role of family income as related to academic performance has never being in doubt (Jeynes 2002; Eamon 2005; Greatz 1995; Considine \& Zappala 2002; Hansen \& Mastekaasa 2006). For instance, family income, according to Escarce (2003) has a profound influence on the educational opportunities available to adolescents and on their chances of educational success. Parker (1999) also reveals that comparatively, low-income parents are more predisposed to a higher level of frustration in their children, and these children are more likely to have poor verbal development and exhibit higher levels of distractibility and hostility in the classroom. Low income of parents or guardians can potentially threaten the stability of the home environment which could negatively impact on the education of their wards. In fact, this is a common feature especially in developing countries where education of children are disrupted due to parents inability to provide adequate school related materials like books while others are made to abandon education altogether to help with parent(s) vocation.

Considine and Zappala (2002) in a study establish that children from families with low income are more likely to exhibit the following patterns in terms of educational outcomes; have lower levels of literacy and comprehension, lower retention rates, exhibit higher levels of problematic school behaviour, are more likely to have difficulties with their studies and display negative attitudes to school. Maurin (2002) concludes that there are varied reasons why 
parental income is potentially a very important determinant of children's academic performance. In fact, rich parents can purchase more of all the basic needs and wants that support children's development and assist them to perform well in school.

\section{Purpose of the Study}

The purpose of this study was to investigate into the effects of parents' socio-economic status on the academic performance of students in the Yamfo Anglican Senior High School in the Brong Ahafo Region of Ghana

\section{Significance of the Study}

The findings of the study has helped us to understand how parental income, parental education and parental occupation as the key elements of the socio-economic status of parents affect the academic performance of students. Also, it has advanced our knowledge in the field that is relevant to academics, policy makers and educational practitioners. For academic, for example, it provided the classroom teacher with the knowledge of flexibility when dealing and handling students from different socio-economic background. For policy makers and educational practitioners, the findings have enabled them to plan and revise the curricular of the school to meet the unique needs of students. Most importantly, since copies were made available in the school library, it has served as a source of reference material for students who are be interested in knowing how the socio-economic status of parents affect the academic performance of students.

\section{Research Questions}

The research sought to provide answers to the following questions;

1. To what extent does the education level of parents affect the academic performance of students?

2. To what extent does the occupation level of parents affect the academic performance of students?

3. To what extent does the income level of parents affect the academic performance of students?

\section{Design of the Study}

\section{RESEARCH METHODOLOGY}

The research design used in the study was a descriptive survey. This research design was deemed appropriate because the phenomenon understudy was looked into at a specific moment and precisely described.

\section{Population and Sampling Procedures}

The target population of the study was the second-year students of Yamfo Senior High School. The form two students from each school were selected because they had been in the school at least for more than a year and therefore stood the better chance to provide useful information. Also, the forms two students were not under any final examination pressure which raised their cooperation and commitment. The total population of the second-year student was 213, out of which 80 students were simple randomly sampled.

\section{Research Instrument}

The instrument for collecting data in this study was self-developed questionnaire. Questionnaires were used because they are the main method of data collection and also the population was literate. Also the coverage of questionnaire is wide as researchers can reach respondents more easily and is unaffected by problems of 'non-contacts'. Again, the popularity of questionnaires is probably based on some advantages among which are its low cost in terms 
of both money and time involved (Sarantakos, 1997). The questionnaire contained both openended and close-ended questions.

\section{Data Analysis Plan}

The collected data was analysed with the use of frequencies, tables and percentages. Thus, research questions one, two and three were analysed via frequencies, tables and percentages.

\section{Research Question 1}

\section{RESULTS AND DISCUSSIONS}

To what extent does the education level of parents affect the academic performance of students? This research question has the sole aim of ascertaining whether parental level of education has any significant effect on the academic performance of the child. The result is presented in Table 1.

Table 1: The Effects on Father's and Mother's Education on the Academic Performance of Students

\begin{tabular}{|c|c|c|c|c|}
\hline Responses & $\begin{array}{l}\text { Father's Education } \\
\text { Frequency }\end{array}$ & Percent & $\begin{array}{l}\text { Mother's Education } \\
\text { Frequency }\end{array}$ & Percent \\
\hline Strongly agree & 26 & 32.5 & 22 & 27.5 \\
\hline Agree & 26 & 32.5 & 28 & 47.5 \\
\hline Uncertain & 1 & 1.2 & 0 & 0.0 \\
\hline Strongly disagree & 9 & 11.2 & 11 & 13.8 \\
\hline Disagree & 18 & 22.5 & 9 & 11.2 \\
\hline Total & 80 & 100 & 80 & 100 \\
\hline
\end{tabular}

The result in Table 1 indicates that the educational level parents affect the academic performance of respondents. In fact, 48 respondents representing $60 \%$ believed that both their father's and mother's educational levels affect their academic performance. Also, 54 respondents representing 80\% thought in a likewise manner. Contrary, 20 and 27 respondents representing 33\% strongly disagreed and disagreed respectively that their father's and mother's educational levels affect their academic performance. Undoubtedly, the findings from this study suggest that majority of the respondents strongly agreed and agreed that the educational level of parents affect their academic performance.

The results from this study turn out to share similar views in the literature reviewed. Most of the literature surveyed establishes that parents' education is positively related to the academic performance of children (Considine \& Zappala, 2002; Eamon, 2005; Jeynes 2002). For example, Annette (2003) argues that academic attainment of parents had a positive and statistically significant effect on the educational attainment of their wards. Tinto (1993) also reveals that there is a strong relationship between a student's academic output and his or her parent's educational qualifications. For him, parents' academic achievements enable their children to build a positive self-efficacy image of themselves which makes them feel they are capable of succeeding in their academic pursuit.

\section{Research Question 2}

To what extent does the occupation level of parents affect the academic performance of students? The rationale behind this research question was to establish the extent to which parents' occupation level affect students' academic performance. Table 2 present the findings. 
Table 2: The Effects on Father's and Mother's Occupation on the Academic Performance of Students

\begin{tabular}{lcccc}
\hline Responses & \multicolumn{2}{c}{$\begin{array}{c}\text { Father's Occupation } \\
\text { Frequency }\end{array}$} & Percent & $\begin{array}{c}\text { Mother's Occupation } \\
\text { Frequency }\end{array}$ \\
& 35 & 43.8 & 34 & 42.5 \\
\hline Strongly agree & 27 & 33.8 & 30 & 37.5 \\
Agree & 4 & 5.0 & 1 & 1.2 \\
Uncertain & 8 & 10.0 & 9 & 11.2 \\
Strongly disagree & 6 & 7.5 & 6 & 7.5 \\
Disagree & $\mathbf{8 0}$ & $\mathbf{1 0 0}$ & $\mathbf{8 0}$ & $\mathbf{1 0 0}$ \\
Total & & & &
\end{tabular}

According to the result in Table 2, the occupational levels of parents affect the academic performance of their wards. Thus, 69 students representing 86.3\% strongly agreed that both father's and mother's occupation affects their academic performance whilst 57 respondents representing $71.3 \%$ also agreed that both their father's and mother's occupation affects their academic performance. On the other hand, 17 and 12 respondents representing $21.2 \%$ and $15 \%$ respectively strongly disagreed and disagreed that both father's and mother's occupation affects their academic performance while 5 respondents representing $6.2 \%$ were not certain as to the extent the occupation level of parents affect their academic performance. Indeed, preponderance of the respondents strongly agreed and agreed that the educational level of parents affect their academic performance in this study.

These findings are consistent with the findings of a number of researchers (Janny \& David, 2005; McNeal, 2001; Graetz, 1995). Combs (1985), for example, argues that virtually in all nations, children of parents high on the occupational scale have far better chance of getting into good secondary schools and from there into the best colleges and universities. Combs, also asserted that a great number of children whose parents are at the bottom of the occupational hierarchy are not as inclined to seek or gain access to available educational facilities compared to children whose families are located at the middle or top of the hierarchy. Dills (2006) in a similar view finds that students from the bottom quartile consistently perform below average compared to students from the top quartile of the occupational status. Indeed, parents' occupation level has a significant effect on the academic achievement of their wards. It plays a remarkable role in students' academic advancement and achievement.

\section{Research Question 3}

To what extent does the income level of parents affect the academic performance of students? The purpose of this research question was to find out whether the income level of parents affects the academic performance of the students. The results are presented in Table 3. 
Osei-Owusu, B., Twum Ampofo, E., Oteng Akyina, K., Ampomah, R., \& Osei-Owusu, E. (2018). Socio-Economic Status Of Parents And Its Effects On The Academic Performance Of Students Of Yamfo Anglican Senior High School In The Brong Ahafo Region Of Ghana. Advances in Social Sciences Research Journal, 5(4) 48-58.

Table 3: The Effects on Father's and Mother's Income on the Academic Performance of Students

\begin{tabular}{lcccc}
\hline Responses & $\begin{array}{c}\text { Father's Income } \\
\text { Frequency }\end{array}$ & Percent & $\begin{array}{c}\text { Mother's Income } \\
\text { Frequency }\end{array}$ & Percent \\
\hline Strongly agree & 29 & 36.3 & 20 & 25.0 \\
Agree & 22 & 27.5 & 23 & 28.8 \\
Uncertain & 2 & 2.5 & 5 & 6.3 \\
Strongly disagree & 17 & 21.3 & 18 & 22.5 \\
Disagree & 10 & 12.5 & 14 & 17.5 \\
Total & $\mathbf{8 0}$ & $\mathbf{1 0 0}$ & $\mathbf{8 0}$ & $\mathbf{1 0 0}$ \\
\hline
\end{tabular}

With reference to results in Table 3, the income of respondents' parents affects their academic performance. For instance, 49 and 45 students representing $61.3 \%$ and $56.3 \%$ respectively strongly agreed and agreed that both their father's and mother's income levels affect respondents' academic performance. However, 35 and 24 respondents representing 48\% and $30 \%$ respectively strongly disagreed and disagreed as to how their academic performance is affected by the income level of their father and mother. Last but not least, 7 respondents representing $7.5 \%$ were indifference as to the effect their parents level of income has on their academic performance. Without a doubt, a chunk of students shared the view point that their academic performance is affected by parents' income.

This result finds a number of supports in the literature reviewed doubt (Jeynes 2002; Eamon 2005; Greatz 1995; Hansen \& Mastekaasa 2006). For instance, family income, according to Escarce (2003) has a profound influence on the educational opportunities available to adolescents and on their chances of educational success. Parker (1999) also reveals that comparatively, low-income parents are more predisposed to a higher level of frustration in their children, and these children are more likely to have poor verbal development and exhibit higher levels of distractibility and hostility in the classroom. Maurin (2002) concludes that there are varied reasons why parental income is potentially a very important determinant of children's academic performance. In fact, rich parents can purchase more of all the basic needs and wants that support children's development and assist them to perform well in school.

\section{CONCLUSION}

In this study, an attempt was made to find out the extent to which the academic performance of the students was affected by the socio-economic status of parents. The study therefore established that the socio-economic status of parents, thus parents' education, parents' occupation and parents' income affected the child's academic performance. This presupposes that the child academic performance was strongly mediated by parents' socio-economic status. This further suggests that when these variables are high, there is the likelihood that students will perform creditably well. I therefore conclude that parents who are fortunate to have sound socio-economic background must encourage their children to be academically ambitious, help them to learn and must try as much as they can to provide their children with all their educational needs. Likewise, parents who are less privilege on socio-economic status must still instill in their children the 'can do spirit'. In fact, this will go a long way to inspire the children to study hard to break that so called 'socio-economic status' jinx.

\section{RECOMMENDATIONS}

On the basis of the findings and conclusions discussed above, the following recommendations are made. 
1 Parents are the foremost agents in nursing their children academic success. In this study, the socio-economic status of parents was found to affect the child's academic achievement. It is therefore recommended parents should be encouraged to get involved in their children's education no matter their socio-economic status.

2 It is strongly recommended that the government should heavily subsidize education at least at the basic level. In fact, needy but brilliant students should be provided with scholarships, free reading materials and other stationeries.

3 Majority of parents are not aware that home environment affects their wards academic performance. It is hence recommended that they must be made aware. Thus, during PTA meetings teachers and heads of schools should sensitize parents the importance of home environment on the child's academic performance. Indeed, parents should be told that they can improve the quality of their children's education through encouragement, provision of educational materials and participation.

\section{References}

Annette, L. (2003). Unequal childhoods: Race, class and family life. University of California Press

Battle, J., \& Lewis, M. (2002). The increasing significance of class. The relative effects of race and socioeconomic status on academic achievement. Journal of Poverty, 6 (2), 21-35.

Burns, A., \& Darling, N. (2002). Peer pressure is not peer influence. The Education Digest, 68, 4-6.

Combs, H. P (1985). The world crisis in education: The view from the eighties. NewYork: Oxford press.

Considine, G., \& Zappala, G. (2002). Influence of social and economic disadvantage in the academic performance of school students in Australia. Journal of Sociology, 38, 129-148.

Dills, K. A. (2006). Trends in the relationship between socioeconomic status and academic achievement. Retrieved September 30, 2013 from http://papers.ssrn.com/

Eamon, M. K. (2005). Social-demographic, school, neighbourhood and parenting influence on academic achievement of Latino young adolescents. Journal of youth and adolescence, 34 (2), 163-175.

Elliot, A. (2007). A conceptual history of the achievement goal construct. In A. Elliot \& C. Dweck (Eds.), Handbook of competence and motivation (pp.52-72). New York: Guilford Press.

Escarce, J. J (2003). Socioeconomic status and the fates of adolescents. Retrieved on September 272014 from http://www.pubmedcentral.nih.gov/

Graetz, B. (1995). Socioeconomic Status in Education Research and Policy. Canberra: DEET/ACER.

Grissmer, R. H. (2003). Beyond helping with homework: Parents and children doing mathematics at home. Teaching Children Mathematics, 14, 120- 131.

Hansen, N. M., \& Mastekaasa, A. (2006). Social origins and academic performance at university. USA: Oxford University Press.

Hijazi, S. T., \& Naqvi, S. M. M. R. (2006). 'Factors affecting students' performance: A case of private colleges'. Bangladesh E-Journal of Sociology, 3 (1), 65-99.

Head, P. (1990). Performance indicators and quality assurance. London: Council for National Academic Awards.

Heyneman, S. P. (2005). Students background and students achievement: What is the question. American Journal of Education, (112), 1-9.

Jeynes, W. H. (2002). Examining the effects of parental absence on the academic achievement of adolescents: The challenge of controlling for family income. Journal of family and Economic Issues, 23 (2), 65-78.

Johnson, V. E. (2003). Grade inflation: A crisis in college education. New York, NY: Springer-Verlag.

Maurin E. (2002). "The impact of parental income on early schooling transitions: A re-examination using data over three generations". Journal of Public Economics, 85 (3), 301-332.

Mbathia, M. (2005). Cream for Law and Medicine. The Standard. Nairobi: The Standard Ltd.

McNeal, R. B. (2001). Differential effects of parental involvement on cognitive and behavioural outcomes by socioeconomic status. Journal of Socio-Economics, 30 (2). 171. 
Osei-Owusu, B., Twum Ampofo, E., Oteng Akyina, K., Ampomah, R., \& Osei-Owusu, E. (2018). Socio-Economic Status Of Parents And Its Effects On The Academic Performance Of Students Of Yamfo Anglican Senior High School In The Brong Ahafo Region Of Ghana. Advances in Social Sciences Research Journal, 5(4) 48-58.

Oakes, J. M., Rossi, R. H. (2002). The measurement of SES in health research: Current practice and steps toward a new approach. Social Science and Medicine, 56, 769-784.

Parson, R. D., Stephanie, L.H., \& Deborah, S. (2001). Educational psychology: A practitioner-researcher model of teaching. Singapore: Thomson Learning Inc.

Saifi, S., \& Mehmood, T. (2011). Effects of socio-economic status on students' achievement. International Journal of Social Sciences and Education, 2, 119-128.

Sarantakos, S. (1997). Social research. New York: Palgrave Publishers Ltd.

Saxton, J. (2000). Investment in education: Private and public returns. Retrieved May 25, 2013 from http://www.house.gov/jec/.

Taiwo, H. G. (1993). Family environment and educational attainment of some school children in western Nigeria. Journal of the Science Teachers Association of Nigeria, 46 (2), 107-116.

Tinto, V. (1993). Limits of theory and practice in student attrition. Journal of Higher Education, 53, 687-700.

Williams, T. (1987). Participation in education. Hawthorn: Australian Council for Education Research 